\title{
Intususcepción de intestino delgado por linfoma a células -T
}

\author{
Moisés Vértiz ${ }^{1,2}$, Manuel García ${ }^{3}$, Herbert Yabar ${ }^{4}$
}

Resumen

Palabras clave
Paciente de sexo femenino, de 53 años de edad, ama de casa, natural del Departamento de Amazonas, procedente de Lima, donde radicaba desde su juventud, fue admitida en Emergencia del hospital por presentar dolor abdominal tipo cólico persistente, en mesogastrio, con irradiación al hemiabdomen superior. Además, presentaba tumoración abdominal, de más o menos $8 \times 5 \times 5 \mathrm{~cm}$, en mesogastrio, móvil, dolorosa y dolor a la descompresión en fosa iliaca derecha; posteriormente, se agregó vómitos en dos oportunidades y pérdida de peso no cuantificado. En el intraoperatorio, se encontró intususcepción del íleon terminal hacia colon ascendente y tumoración de íleon distal. La anatomía patológica de la tumoración demostró linfoma no Hodgkin, fenotipo de células $T$ de grado alto de malignidad.

Linfoma de células T; intestino delgado; intususcepción; cirugía.

\section{Small bowel intussusception due to T-cell lymphoma}

Abstract

Female patient FPM, 53 year-old, housewife, born in Amazonas, Peru, resident in Lima since teenager, was admitted at Emergency room due to colicky abdominal pain and abdominal tumour about $8 \times 5 \times 5 \mathrm{~cm}$, in mesogastric area, mobile and painful. She had vomiting in two opportunities and lost undetermined weight. During surgery we found terminal ileum intussuception into the ascending large bowel and a tumour mass in terminal ileum. Pathology report informed high degree of malignancy no-Hodgkin T-cell phenotype lymphoma.

Key words: Lymphoma, T-cell; intestine, small; intussusception; surgery.

\section{INTRODUCCIÓN}

Los tumores malignos del intestino delgado son relativamente infrecuentes, representan 1 a $4 \%$ de

1 Departamento Académico de Cirugía, Facultad de Medicina - Universidad Nacional Mayor de San Marcos. Lima, Perú.

2 Jefe de Servicio de Cirugía, Hospital Nacional Edgardo Rebagliati Martins - Essalud. Lima, Perú.

3 Departamento de Medicina, Facultad de Medicina - Universidad Nacional Mayor de San Marcos. Lima, Perú.

4 Jefe de Departamento de Patología Hospital Nacional Edgardo Rebagliati Martins - Essalud. Lima, Perú. todos los tumores del tracto gastrointestinal $\left({ }^{1}\right)$. Los linfomas del intestino delgado corresponden de 10 a $15 \%$ de todos los tumores malignos localizados en él, pudiendo ser primarios o parte de una enfermedad generalizada $\left({ }^{2,3}\right)$. Para ser considerados primarios, bajo los criterios de Davison y col. $\left({ }^{4}\right)$, deben tener las siguientes condiciones:

a. Ausencia de linfadenopatía periférica.

b. Radiografía de tórax normal sin crecimiento de ganglios mediastinales.

c. Cuenta de leucocitos total y diferencial normales.

d. En la pieza operatoria debe predominar la lesión intestinal y los ganglios afectados corresponder a ella.

e. Ausencia de compromiso de hígado y bazo.

Los linfomas gastrointestinales representan la localización extraganglionar más común de todos los linfomas no Hodgkin (4 a 20\%), mientras la localización gástrica es la más frecuente $(50$ a $60 \%$ ), seguida del intestino delgado (20 a 30\%), colon $(9 \%)$ y multifocal $(8 \%)$.

Los síntomas, en orden de frecuencia, son dolor abdominal (70\%), vómitos (48\%), pérdida 
ponderal (44\%), tumoración abdominal (24\%), melena y/o hematoquesia ( $22 \%$ más frecuente en localización gástrica), diarrea $(16 \%)$, anorexia (12\%) y estreñimiento (7\%). Más de $50 \%$ de pacientes tiene de 2 a 4 de los síntomas señalados y el promedio de duración de los síntomas va de 6 a 10 meses $\left({ }^{1,5}\right)$.

Un 15 a $20 \%$ de los casos son atendidos como emergencias quirúrgicas, como sangrado digestivo (más frecuente en localización gástrica), perforación (más frecuente en localización intestinal) $\mathrm{y}$, con menor grado de frecuencia, obstrucción e intususcepción $\left({ }^{6,7}\right)$.

La citología y el grado de agresividad dependen del tipo de linfoma no Hodgkin, lo que tendrá estrecha relación con el pronóstico de la enfermedad.

Según la clasificación de Isaacson, muy utilizada para esta patología, los linfomas gastrointestinales son clasificados en $\left(^{5}\right)$ :

1. Linfoma de células B

- Tipo Malt.

- Grado bajo.

- Grado alto, con o sin componente de grado bajo asociado.

- Enfermedad inmunoproliferativa de intestino delgado, de grado bajo o alto, con o sin componente de grado bajo.

- Poliposis linfomatosa.

- Linfoma de Burkit y parecido a Burkit.

- Otros tipos de linfoma de grado bajo o alto, correspondientes a linfoides ganglionares equivalentes.

2. Linfomas de células $\mathrm{T}$

- Asociados a enfermedad celiaca o enteropatía.

- Otros linfomas T no asociados a enteropatía.

Aproximadamente, $85 \%$ de los casos corresponde al tipo B y $15 \%$ al tipo T. En la localización ileocecal, como es el caso que presentamos, es sumamente rara la presencia de linfoma tipo $\mathrm{T}$.

Por otro lado, los linfomas gastrointestinales son más frecuentes en varones que en mujeres, en proporción de $2: 1$, siendo la edad media del diagnóstico entre 50 y 60 años $\left({ }^{8}\right)$

Los factores pronósticos en linfomas gastrointestinales primarios son: estadio tumoral, edad de presentación (peor en edades extremas), modo de presentación clínica (peor si hay perforación intestinal), estado general del paciente, masa tumoral mayor de $7 \mathrm{~cm}$, histología y grado de agresividad, invasión de la pared, presentación de inmunosupresión asociada y multifocalización. Los linfomas tipo $\mathrm{T}$ son de peor pronóstico ${ }^{6}$ ).

\section{CASO CLÍNICO}

La paciente presentó los siguientes antecedentes: en 1976, ligadura de trompas y herniorrafia umbilical; en 1993, colecistectomía abierta; en 1996 y 2002, hernioplastia inguinal bilateral. No había recibido transfusiones ni tenía antecedentes de hipertensión, asma, tuberculosis, hepatitis, cardiopatía. G 5005.

En la enfermedad actual, hacía un mes que presentaba dolor abdominal difuso, tipo cólico, intermitente, de leve intensidad, náuseas, sin vómitos ni fiebre. Una semana antes de su ingreso, luego de tomar laxante, refirió deposiciones líquidas, como lavado de carne, en regular cantidad, 5 cámaras al día, con moco y sangre, dolor abdominal cólico persistente en mesogastrio con irradiación al hemiabdomen superior; además, presencia de tumoración abdominal de más o menos $4 \mathrm{~cm}$; luego, se agregó vómitos (dos) y ardor al orinar. Tuvo baja de peso no cuantificada. Al examen clínico, se observó una paciente en aparente regular estado general, adelgazada; el abdomen era simétrico. Con ruidos hidroaéreos presentes, dolor en mesogastrio y fosa iliaca derecha a la descompresión. Se palpó tumoración abdominal de $8 \times 5 \times 5 \mathrm{~cm}$, en mesogastrio, móvil, dolorosa, de bordes más o menos definidos. Signos de Mc Burney + , Rousing + , Blumberg -. Percusión lumbar derecha + . El resto del examen fue normal. 
Exámenes auxiliares: Glucosa $113 \mathrm{mg} \%$, urea $21 \mathrm{mg} \%$, creatinina $1,24 \mathrm{mg} \%$, sodio $137 \mathrm{mEq} / \mathrm{L}$, potasio $4,5 \mathrm{mEq} / \mathrm{L}$, grupo $\mathrm{O} \mathrm{Rh}+$, leucocitos 7120 , neutrófilos $66 \%$, linfocitos $20,5 \%$, monocitos $8,4 \%$, eosinófilos $4,6 \%$, basófilos 0,02 . Hemoglobina $11,2 \mathrm{~g} \%$, hematocrito 34,2 , plaquetas 355000 , tiempo de protrombina 11,8 ", tiempo de trombina 35,2", fibrinógeno $690 \mathrm{mg}$. Orina con sangre ++ . Thevenon en heces ++ . Ecografía abdominal mostró tumoración hipoecoica en flanco derecho, al parecer dependiente del intestino. Ecografía pélvica del 12-06-03, normal. Tomografía axial computarizada del 12-06-03 mostró tumoración sólida de $65 \times 53 \mathrm{~mm}$, en flanco derecho, gran dilatación de asas delgadas, con edema de pared; nivel hidroaéreo que sugiere suboclusión intestinal; resto, normal. Diagnósticos probables: plastrón apendicular, tumoración del ciego, quiste de ovario. El tránsito intestinal encontró asas delgadas, hacia la izquierda; no se apreciaba contraste en el marco colónico. El riesgo quirúrgico cardiológico fue grado II.

Al paciente se le realizó una laparotomía exploradora cuyo reporte operatorio del 21-06-03 fue laparotomía exploradora, hemicolectomía derecha y anastomosis ileocólica término-lateral. Hallazgos: intususcepción de íleon terminal hacia colon ascendente, llegando hasta el tercio proximal del colon transverso.

La evolución postoperatoria fue buena y la paciente salió de alta el 01-07-03.

El informe anatomopatológico de la pieza operatoria fue: linfoma no Hodgkin de fenotipo $\mathrm{T}$, de alto grado de malignidad, ubicado en íleon distal, de $7 \times 4 \times 4 \mathrm{~cm}$, ovoidea, que causa intosuscepción hacia ciego. Bordes quirúrgicos libres de neoplasia. Apéndice cecal sin alteraciones. Ganglios linfáticos regionales comprometidos 1/11. Meso, congestivo. Ganglios linfáticos, libres de neoplasia $0 / 2$.

Tomografía axial computarizada: Microadenopatías retroperitoneales.

Biopsia de hueso 20-8-03: no evidencia de malignidad en la muestra. Survey óseo normal. HTLV1 no reactivo. Marcadores tumorales: proteínas totales $8,01 \mathrm{~g}$, albúmina 4,51, globulina
3,50 , fosfatasa alcalina 97 , microglobulina B2 $3,20(\mathrm{~N} 0,8$ a 2,2).

TGP 25 UI, TGO 60 UI, deshidrogenasa láctica 330.

Evaluación por Oncología Médica: linfoma intestinal no Hodgkin, estadio II-B.

El 19-08-03 se le programó 5 ciclos de quimioterapia, con ciclofosfamida + doxorrubicina + vincristina + prednisona. Hubo un segundo ciclo el 12-09-03, tercer ciclo el 15-10-03, cuarto ciclo el 10-11-03 y quinto ciclo el 12-12-03.

La evolución hasta la fecha es favorable.

\section{DISCUSIÓN}

La publicación del presente caso clínico es motivada por lo infrecuente de la forma de presentación en adultos (menos de $10 \%$ de todos los linfomas) $\left(^{5}\right)$ y por el tipo histológico (linfoma de células T), de rara ocurrencia en el íleon terminal $\left({ }^{9}\right)$.

Las manifestaciones clínicas del presente caso se reúnen en cinco síntomas-signo destacables: dolor abdominal, náuseas, hematoquesia, tumoración abdominal y baja ponderal de un mes de evolución, en concordancia con lo señalado por estudios previos $\left({ }^{4}\right)$.

El grupo etario más afectado en adultos por este tipo de neoplasias oscila entre 50 y 60 años $\left({ }^{3,10}\right)$.En cuanto a la distribución por sexo, la proporción es de $2: 1$, a favor del sexo masculino $\left({ }^{6,10}\right)$. Las edades extremas son de peor pronóstico $\left({ }^{4}\right)$.

La palpación de una tumoración abdominal de $8 \times 5 \times 5 \mathrm{~cm}$ y que en el estudio anatomopatológico de la pieza operatoria tuvo dimensiones de $7 \times 4 \times 4 \mathrm{~cm}$ es de suma importancia, por cuanto las investigaciones previas han demostrado que el tamaño tumoral es un factor pronóstico agravante, cuando supera los $7 \mathrm{~cm}\left({ }^{1,4}\right)$.

El hallazgo en ecografía y tomografía axial computarizada demostraron tumoración sólida, con dilatación de asa delgada, edema de pared y nivel hidroaéreo, que sugería suboclusión intestinal. El 


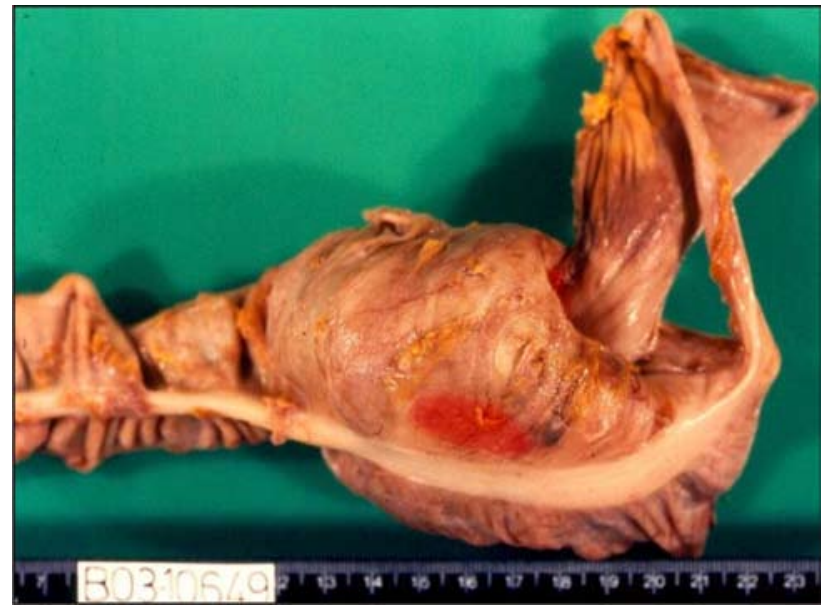

Figura 1. Intusucepción del íleon terminal en el colon ascendente.

hallazgo intraoperatorio de intususcepción del íleon terminal hacia el colon ascendente (Figuras 1 y 2), que motivó una hemicolectomía derecha, es una presentación infrecuente, por cuanto en el intestino delgado se la describe como complicación quirúrgica (de 15 a $36 \%$ de los linfomas intestinales), siendo más frecuentes la perforación intestinal y la obstrucción $\left({ }^{3,11}\right)$.

El estudio anatomopatológico del presente caso demostró la presencia de linfoma no

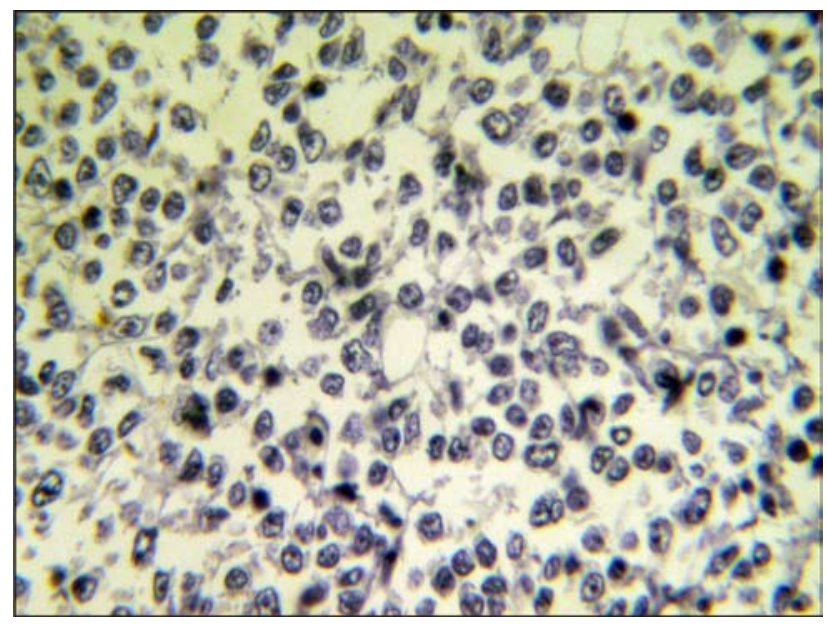

Figura 3. La inmunorreacción para CD-20 es negativa.

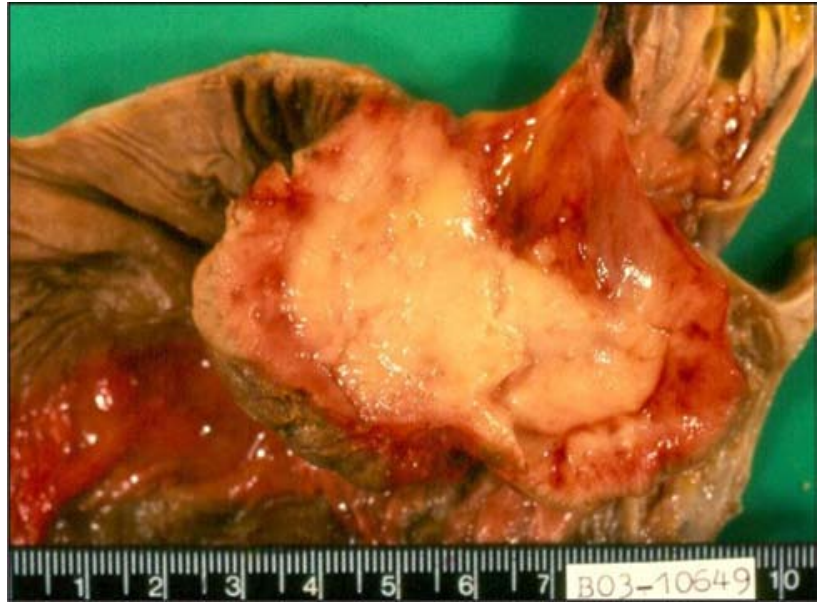

Figura 2. Corte de la tumoracion de íleon terminal.

Hodgkin, de fenotipo a células $\mathrm{T}$, de alto grado de malignidad, en íleon distal, y ganglios regionales comprometidos 1/11 (Figuras 3 y 4). Dicho tipo de tumor corresponde en la literatura a $15 \%$ de los linfomas intestinales y con un comportamiento más agresivo que los linfomas a células $\mathrm{B}\left({ }^{2}\right)$.

La sobrevida a 5 años de tumores intestinales se describe, en carcinomas $37 \%$, en carcinoides $64 \%$, en linfomas $29 \%$ y sarcomas $22 \%\left({ }^{1}\right)$.

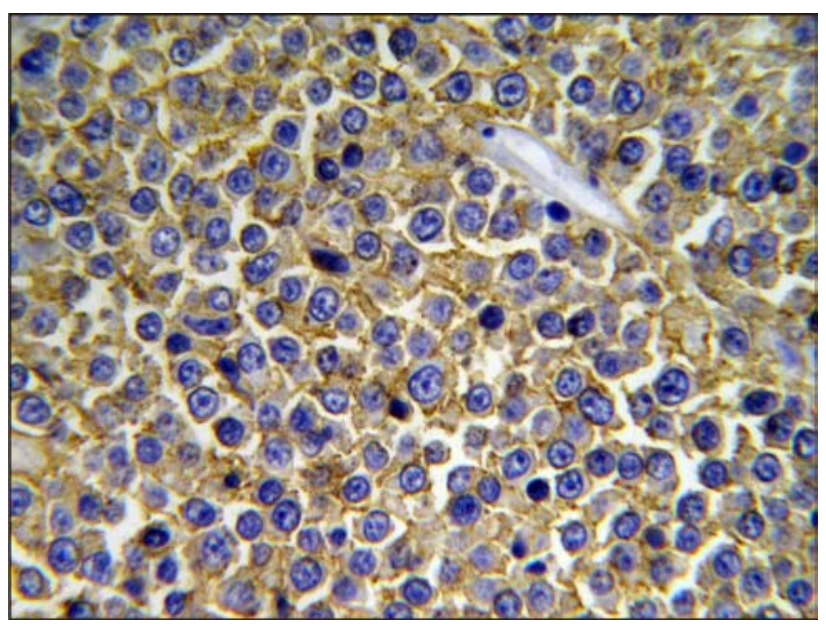

Figura 4. La inmunorreacción para CD-3 es positiva, en relación a un fenotipo $\mathrm{T}$. 
El estadiaje correspondiente al presente caso es el II-B, según Ann Arbor, modificada por Musshoff ${ }^{(3)}$. La cirugía es requerida para el estadiaje, encontrándose que los estadios I-B y II-B corresponden a $71 \%$ y los estadios III y IV, a $29 \%\left({ }^{4}\right)$.

Aún no está definido claramente el tratamiento final, por su poca frecuencia y variedad histológica. Este tratamiento puede ser solo quirúrgico en el estadio I-B; quirúrgico más quimioterapia adyuvante, en el estadio II-B; o quimioterapia más radioterapia y antibioticoterapia (40\% de los linfomas gástricos se asocian a Helicobacter pylori y han remitido con tratamiento antibiótico) $\left.{ }^{5,12}\right)$.

El caso presentado ha tenido tratamiento quirúrgico y quimioterapia adyuvante de 5 ciclos, presentando remisión completa a diciembre de 2006 evidenciando buena evolución clínica $\left({ }^{13}\right)$.

\section{REFERENCIAS BIBLIOGRÁFICAS}

1. Talamonti MS, Goetz LH, Rao S, Joehl RJ. Primary cancers of small bowel: analysis of prognostic factors and results of surgical management. Arch Surg. 2002;137:564-71.

2. Chim CS, Loong F, Leung AY, Tsang J, Ooi GC. Primary follicular lymphoma of the small intestine. Leuk Lymphoma. 2004;45(7):1463-6.

3. Lee J, Kim WS, Kim K, Ko YH, Kim JJ, Kim YH, et al. Intestinal lymphoma: exploration of the prognostic factors and the optimal treatment. Leuk Lymphoma. 2004;45(2):33944.

4. Molina R, Jiménez A. Linfoma T primario intestinal: a propósito de 2 casos, con revisión de la literatura. Anal Med Int (Madrid). 2002;19(9):457-9.

5. Leone N, Brunello F, Baronio M, Giordanino C, Morgando A, Marchesa P, et al. High grade B-cell lymphoma arising in mucosa-associated lymphoid tissue of the duodenum. Eur J Gastroenterol Hepatol. 2002;14(8):893-6.

6. Dragosics B, Bauer P, Radaszkiewicz T. Primary gastrointestinal non-Hodgkin's lymphomas. A retrospective clinicopathologic study of 150 cases. Cancer. 1985;55:106073.

7. Radman I, Kovacević-Metelko J, Aurer I, Nemet D, Zupancić-Salek S, Bogdanić V, et al. Surgical resection in the treatment of primary gastrointestinal non-Hodgkin's lymphoma: retrospective study. Croat Med J. 2002;43:55560.

8. Aozasa K, Ueda T, Kurata A, Kim CW, Inoue M, Matsuura N, et al. Prognostic value of histologic and clinical factors in 56 patients with gastrointestinal lymphomas. Cancer. 1988;61:309-15.

9. Isaacson PG. Gastrointestinal lymphoma. Hum Pathol. 1994;25:1020-9.

10. Lazos M, Valdés R. Linfomas intestinales. Rev Med Hosp Gen Mex. 1998:61(1).

11. Amer M, El Akkad S. Gastrointestinal lymphoma in adults: Clinical feature and management of 300 cases. Gastroenterol. 1994;106:846-58.

12. Ivorra HT. Enfermedad celíaca, esprúe refractario y linfoma intestinal. Rev Soc Valencia Patol Digest. 2002;21(2):1024.

13. Nomura K, Tomikashi K, Matsumoto Y, Yoshida N, Okuda T, Sakakura C, et al. Small bowel non-Hodgkin's lymphoma remaining in complete remission by surgical resection and adjuvant rituximab therapy. World J Gastroenterol. 2005;11: 4443-4.

Manuscrito recibido el 22 de junio de 2007 y aceptado para publicación el 05 de setiembre de 2007.

Correspondencia:

Dr. Moisés Vértiz Herbozo

Av. Dintilhac 233 Urb. Pando. San Miguel

Lima 32, Perú

Correo-e: migarciarojas@hotmail.com 